Article

\title{
Comparison of the Location and Rating of Energy Storage for Renewables Integration in Residential Low Voltage Networks with Overvoltage Constraints
}

\author{
Andrew F. Crossland ${ }^{1}$, Darren Jones ${ }^{2}$, Neal S. Wade ${ }^{3}$ (D) and Sara L. Walker ${ }^{3, *}$ (D) \\ 1 Infratec, Te Aro, Wellington 6011, New Zealand; andrew.crossland@infratec.co.nz \\ 2 Electricity North West Limited, Warrington WA3 6XG, UK; darren.jones@enwl.co.uk \\ 3 School of Electrical and Electronic Engineering, Newcastle University, Newcastle NE1 7RU, UK; \\ neal.wade@newcastle.ac.uk \\ * Correspondence: sara.walker@newcastle.ac.uk; Tel.: +44-191-208-7261
}

Received: 28 June 2018; Accepted: 3 August 2018; Published: 6 August 2018

\begin{abstract}
Expansion of photovoltaic (PV) generation is increasing the challenge for network operators to keep voltages within operational limits. Voltage rise occurs in low voltage (LV) networks when distributed generators export, particularly at times of low demand. However, there is little work quantifying the scale of voltage issues and subsequently potential solutions across large numbers of real networks. In this paper, a method is presented to analyse a large quantity of geographically and topographically varying distribution networks. The impact of PV on voltages in 9163 real LV distribution networks is then quantified. One potential mitigation measure is increased network demand to reduce voltages. In this work, location algorithms are used to identify where increased demand, through energy storage, has the greatest effect on overvoltage. The study explores the impact on overvoltage of two modes of storage installation reflecting differing routes to adoption: purchase of storage by homeowners and purchase by network operators. These scenarios are compared with traditional re-conductoring in the 9163 networks. It is shown that to avoid violation of absolute voltage limits, storage should be installed at strategically important locations. Storage in homes reduces overvoltage, offering clear benefits to the network operator, but very wide deployment is required to completely remove the need for reinforcement.
\end{abstract}

Keywords: battery energy storage systems; planning; distributed generation; low voltage distribution network

\section{Introduction}

Photovoltaics (PV) are increasingly common in modern electrical power system around the world, with $74 \mathrm{GW}$ of PV installations world-wide in 2016. For example, UK Government statistics show that at least 12.6 GW of PV has been installed by November 2017 [1]. Although PV helps contribute to a decarbonised energy supply, they change the operation of electricity networks, particularly for domestic installations since they are widely installed in random locations in the system [2]. One specific impact of reverse power flow from PV is overvoltage, which can lead to generation curtailment during times of low demand [3]. This means that existing grids may need to be upgraded to accommodate increasing amounts of PV [4]. This can be a particular issue in low voltage (LV) networks due to the expansion of residential PV systems and is a challenge for distribution network operators (DNOs). Energy storage is recognised as one technology which can prevent overvoltage by reducing PV export into the grid [5-7].

From a DNOs perspective, it is important to anticipate how widespread voltage problems will be and how expensive they will be to overcome. This can be achieved by assessing a large number of LV 
networks under differing PV integration scenarios. LV models can be automatically generated using a statistical approach [8] or using cluster analysis to develop prototypical feeders [9]. This can develop a large number of network models, but there is no guarantee that these are entirely representative of a particular DNO area. Scottish and Southern Energy (SSE) trialled a computational procedure to extract representative network models from GIS (geographic information system) data. This was performed over a small section of network to investigate the impact of PV, electric vehicles and heat pumps [10]. Despite the availability of such techniques for network model extraction from GIS, there are few examples of using a large number of such models to assess PV or storage across a wide number of LV networks. Storage is becoming increasingly common due to the advent of new home storage products and has a number of benefits to homeowners such as bill reduction and increased PV self-consumption as part of a home energy management system [11,12]. Batteries can reduce grid consumption by more than $70 \%$ in some cases [13]. Energy storage offers benefits to DNOs and domestic storage has the potential to provide other roles in a "smart" electricity system [14]. These include network support, infrastructure upgrade deferral and ancillary services. Aggregating these provides the most benefits [15].

Although beneficial to homeowners, consideration of the benefits of storage for both homes with $\mathrm{PV}$ and the wider power system is important. If batteries are sized for home use, they may be fully charged by midday, and therefore not contributing to reduce reverse power flow into the grid and consequent voltage rise [12,16]. To address this, battery charging/discharging control needs to reflect both the needs of the customer and network and/or system operators.

There are two distinct propositions for storage in LV networks investigated: (1) installation by homeowners and commercial customers for increased self-consumption and (2) installation directly onto the grid by electricity network operators to manage network power flow (Figure 1). These propositions have previously been studied by the authors and others on a small number of networks $[17,18]$ and in this paper we show the propositions over a large number of networks and draw deeper insights by doing so.

For network operators, there is a specific problem in modelling the cost impact of solar PV and energy storage across a wide number of their networks. This is because much work in the study of PV has focused on specific planning tools on a small number of "typical" networks. In this paper we assess whether a new planning framework can perform a techno-economic comparison of battery energy storage propositions across an entire fleet of LV networks in one study. Specifically, we apply the framework to 9163 LV networks derived from a UK DNO's GIS network map. By doing so this paper addresses two challenges:

1. Comparison of storage in homes to energy storage directly on the network (referred to here as "on the street") as a means of regulating LV network voltages.

2. Examination of a financial case for storage in LV networks.

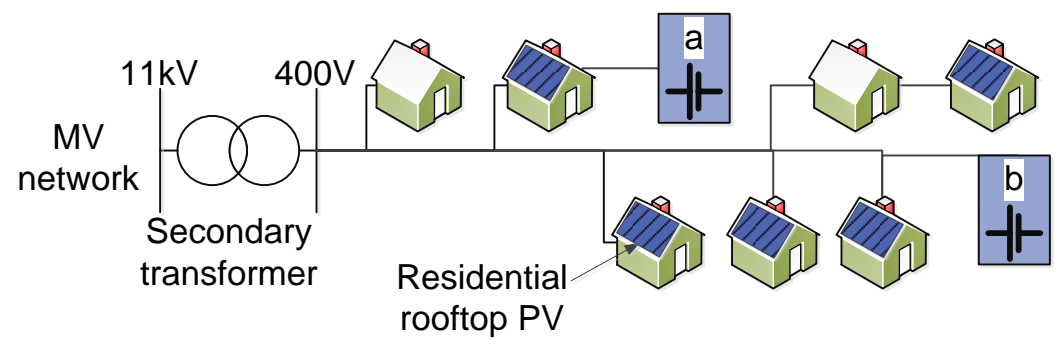

Figure 1. Locations for low voltage (LV) storage showing (a) storage in homes owned by customers and (b) storage located on the street. 


\section{Theory}

LV networks in the UK are made up of one or more secondary transformers and one or more LV feeders. The LV feeders can split into different branches. Loads are connected to the feeders along their length. In urban-residential LV networks, the feeders are usually three phase, four core cables and loads are usually single phase at $230 \mathrm{~V}$ nominal. In the UK, the voltage must not fall below $217 \mathrm{~V}$ for $95 \%$ of the weekly $10 \mathrm{~min}$ rms values, and must be within the range $195.5-253 \mathrm{~V}$ at all times. Overvoltage, even for a short time, is specifically banned under British and European standards [19].

One of the impacts that PV has on networks is overvoltage. This is as a result of the PV injecting power into the network and creating voltage rise, $\Delta V_{\mathrm{LV}}^{+}$The headroom for voltage rise in an LV network is the total allowable voltage deviation in a network minus the total voltage deviation at the secondary transformer, $\Delta V_{\mathrm{T}}$ and the highest voltage drop across the $\mathrm{LV}$ network, $\Delta V_{\mathrm{LV}}^{-}$, as in:

$$
\Delta V_{\mathrm{LV}, n}^{+} \leq 0.16-\Delta V_{\mathrm{T}}-\Delta V_{\mathrm{LV}, n}^{-}-V_{\mathrm{S}}
$$

where $n$ is the index of $N$ networks and $V s$ is a safety margin.

A network is considered to have overvoltage if equality (1) is exceeded. In this paper, it is assumed that the voltage at the secondary transformer has its highest and lowest values when the LV voltages are highest and lowest (to avoid needing MV network modelling). Consequently, a safety margin, $V_{S}$, of 0.01 p.u. is applied in (1). The maximum voltage drop occurs when there is maximum demand and minimum generation. Similarly, voltage rise is highest when PV is exporting maximum power and demand is lowest. This approach means that two loading conditions (high and low voltage) need to be modelled to determine if a network always operates within voltage limits. Accordingly, it allows many networks to be assessed using reasonable computational effort.

\section{Method}

In this paper, we propose a new method for comparative analysis of energy storage integration across a wide number of networks. The results of applying this to a wide variety of networks presents a novel contribution to the scale of overvoltage issues and the present and future ability of energy storage to mitigate these issues.

A number of tools have been combined to examine the following factors for LV networks.

- The impact of output from randomly located residential PV on LV voltage, and quantification of the number of networks with overvoltage.

- The reduction in overvoltage if storage is randomly located in homes with PV systems.

- The minimum amount of storage needed on the street to prevent overvoltage.

An algorithm is proposed to compare strategies, from the perspective of a network operator, for deploying energy storage in low voltage networks to mitigate the overvoltage issues associated with domestic solar PV installations. The algorithm performs simulation and evaluation to determine the strategy with the lowest reinforcement cost for the DNO across all of their networks, thus providing a view of their whole system. In the following section this method is explained in detail including the formulae used to establish and evaluate the alternative storage scenarios.

\subsection{Network Models}

The method outlined in Figure 2 is designed to assess a number, $N$, of LV networks in a loop. Firstly, a model is built of each network, $n$. Loads are set at their maximum value with no PV installed and the voltage drop, $\Delta V_{\mathrm{LV}}^{-}$, is determined using a load flow.

In order to provide comparative analysis, the method first stochastically locates solar PV within the network. Critically, the location of the PV is kept constant whilst an assessment of DNO located storage is performed (box 1). The storage from this algorithm is removed from the model and then a 
second tool is used (box 2) to assess storage randomly installed in domestic properties. This means that both location methods are compared to the same underlying solar PV distribution.

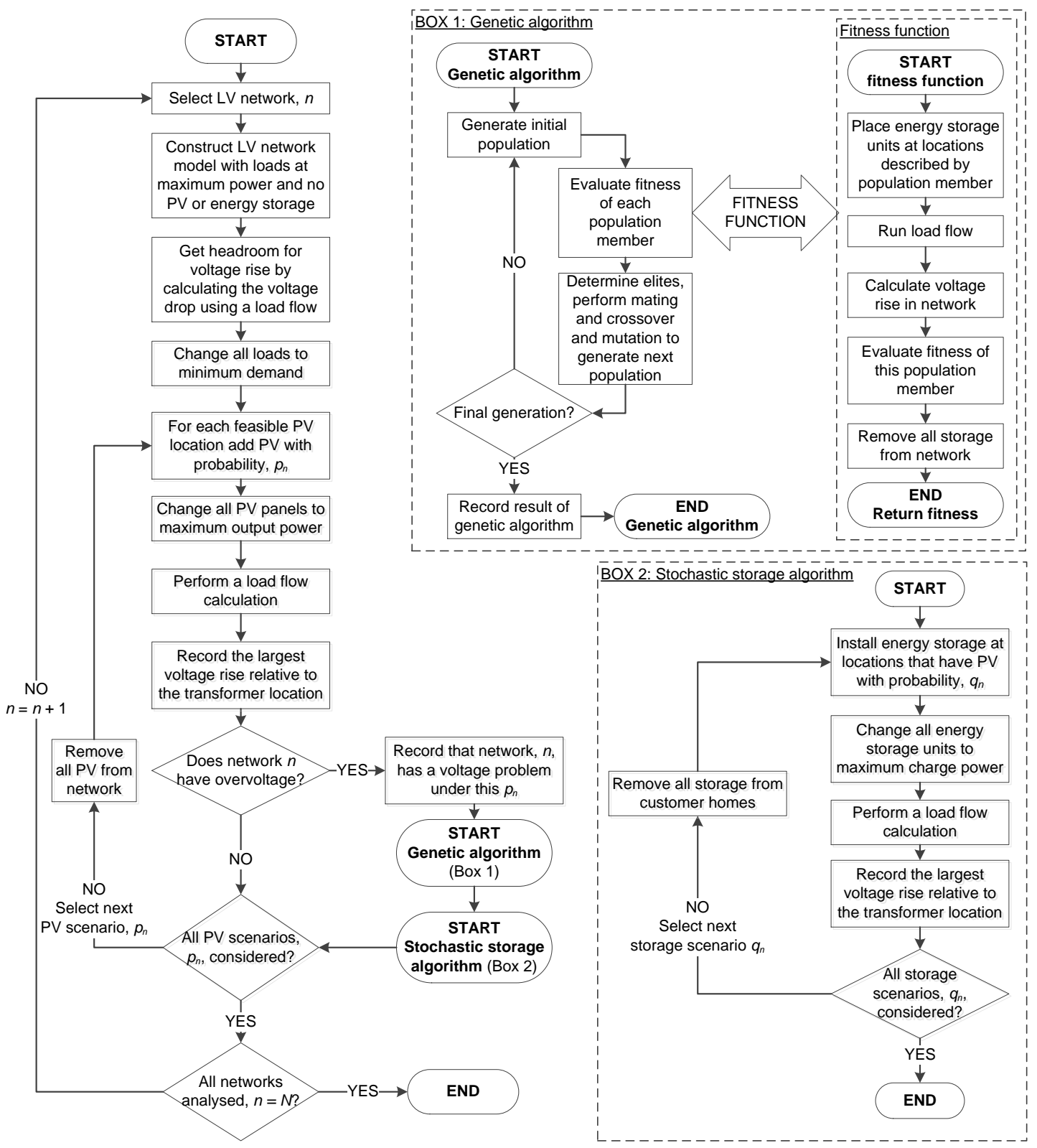

Figure 2. Proposed method for assessing the impact of multiple photovoltaic (PV) dispersion levels, $p_{n}$, on the voltage regulation in multiple LV networks and the subsequent effect of energy storage randomly installed in customer homes with dispersion $q_{n}$ or sited by DNOs, to manage overvoltage.

\subsection{Assessment of $P V$ on Voltage}

To examine the impact of randomly located PV on residential LV networks, a stochastic procedure is used. This is similar to approaches used in $[20,21]$ but applied specifically to assess overvoltage due to residential PV. Each home in $n$, has a fixed probability, $p_{n}$, of installing PV of rating $P_{P V}$. To determine the voltage rise, $\Delta V_{\mathrm{LV}, n}^{+}$, all loads are set to their minimum daytime value and all $\mathrm{PV}$ is set to export rated power. A load flow then calculates voltages. If overvoltage is found, then a storage assessment is performed. 


\subsection{Energy Storage Assessments}

\subsubsection{DNO Owned Energy Storage}

If DNOs are to use storage in networks to provide voltage support, the storage needs to be correctly located to provide the voltage support for the lowest cost [22]. Procedures for locating storage include genetic algorithms [23]. In this paper, a genetic algorithm is used as this has been shown to be able to determine storage locations in LV networks in a short time [24]. This attempts to minimise the total installation cost of storage within the network, but with a fixed penalty if that network exceeds voltage limits. Each population member in the algorithm is a binary number which defines whether storage is installed at each of the nodes of the network and the algorithm returns the combination of storage locations in network, $n$, which eliminates overvoltage for the lowest cost. As opposed to the work in [24] the genetic algorithm is implemented using a genetic algorithm in the Matlab Global Optimisation Toolbox (see Figure 2, box 1) and the fitness function has been simplified to just contain the cost of energy storage. The genetic algorithm converges to a solution that prevents overvoltage with fewest storage units in the network. A fitness function is developed to attribute a cost to each set of storage locations. The fitness function, $f$ is the number of storage units, $N_{E S}$, multiplied by the cost of each, $C_{E S}$, plus a penalty if it does not prevent overvoltage:

$$
f=N_{\mathrm{ES}} C_{\mathrm{ES}}+\left\{\begin{array}{cl}
0 & \text { if voltage within limit } \\
\rho V_{\mathrm{dev}} & \text { if voltage outside limits }
\end{array}\right.
$$

The penalty, $\rho$ is multiplied by the total overvoltage $V_{\mathrm{dev}}$. In [25], a $\rho$ of 150,000 is found to be an appropriate penalty to allow the optimisation to converge to a minimal cost solution. Storage is assumed to be of the same rating, $P_{\mathrm{ES}}$, is 3-phase and can be located at any network node.

\subsubsection{Energy Storage Owned by Customers}

Once the case for DNO storage is completed, an assessment is performed to determine if storage randomly purchased by homeowners can reduce the number of networks which experience overvoltage, and how much re-conductoring will be required by DNOs to prevent overvoltage in each case. To do so, for each network, a proportion $q_{n}$ of the homes with PV purchase and install an energy storage system. As shown in Figure 2, box 2, this is assessed using a loop.

All storage is first taken out of the network and then reinstalled in each home with PV with probability $q_{n}$. A load flow is then used to calculate the voltage rise, $\Delta V_{\mathrm{LV}, n}^{+}$. If there is over-voltage, this is recorded. This process is repeated for all storage dispersion levels $q_{n}$. Storage is represented as a load charging to absorb excess PV with rating $P_{\mathrm{ES}}$.

\subsection{Description of Case Study}

An outline of the case study is now given. It is implemented in Matlab using OpenDSS network models for load flows.

\subsubsection{Extracting LV Networks}

In this study, 9163 LV networks have been extracted from a DNOs GIS. The GIS details the location of all of the LV cables, secondary transformers and homes and is a mandatory requirement for network operators in Britain [26]. A customised procedure for extracting the LV networks has been developed for this paper as described in [24,25]. This is a similar approach to [10]. A DNO from the North West of England (ENWL) provided the GIS. They operate a distribution network serving around 5 million people.

To ensure the reliability of the GIS extraction process, only networks that conform to the criteria in Table 1 are used. The criteria describe typical characteristics of networks serving predominantly residential loads. All are radial and comprise underground cables as is common on this ENWL system 
(and typical for many other urban locations in the UK). Table 2 summarises the network properties and gives the re-conductoring cost, based on the DNO's figure of $£ 80 / \mathrm{m}$.

Table 1. Criteria to which all the networks adhere.

\begin{tabular}{ccc}
\hline Parameter & Minimum & Maximum \\
\hline Homes on most loaded feeder & $\mathrm{n} / \mathrm{a}$ & 200 \\
Total number of loads & 50 & 1200 \\
Length of feeder $(\mathrm{m})$ & 10 & 800 \\
Total cable length $(\mathrm{m})$ & 50 & 12,000 \\
Number of feeders & 1 & 25 \\
\hline
\end{tabular}

Table 2. Summary of networks analysed.

\begin{tabular}{cc}
\hline Parameter & Value \\
\hline Number of networks produced & 9163 \\
Number of feeders in networks & 43,816 \\
Total length of feeder cable, $\mathrm{km}$ & 26,916 \\
Number of homes & $1,666,030$ \\
Homes fit for PV (roofs $\pm 50^{\circ}$ of south) & 910,366 \\
Cost to replace cables ( $£$ millions) & 2153.26 \\
\hline
\end{tabular}

\subsubsection{PV Scenarios}

A forecast of how PV is expected to be installed has been provided by ENWL (Figure 3). This has been combined with GIS data showing the number of homes with roofs facing $\pm 50^{\circ}$ of due south (Table 2) to give projected PV dispersion levels, $p_{n}$ in each network $n$. Each PV installation is assumed to have a capacity of $P_{\mathrm{PV}}=3.6 \mathrm{kWp}$ as this is the average size in the ENWL network.

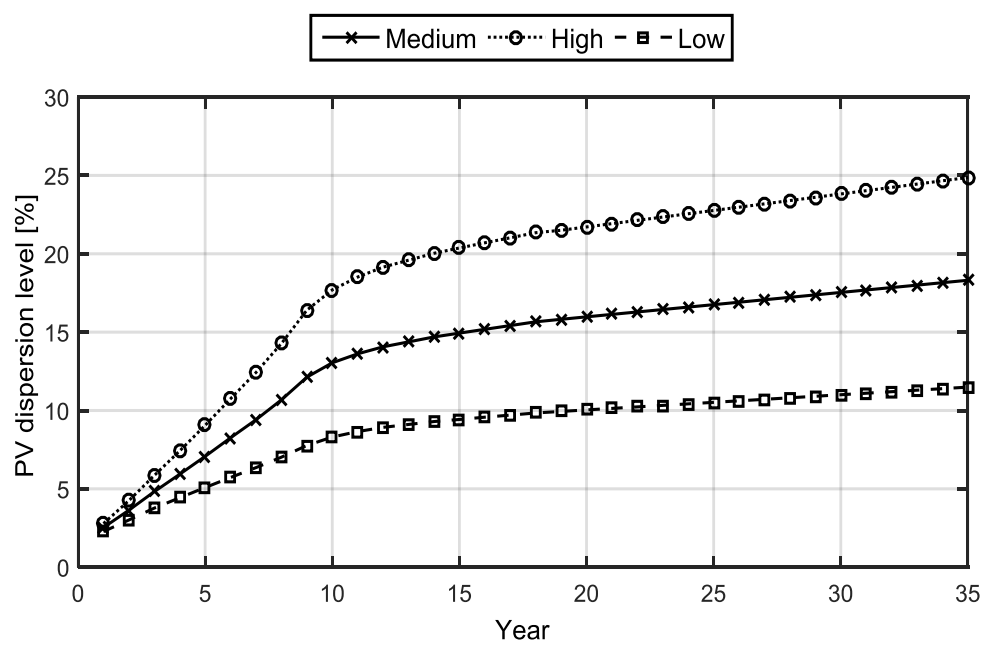

Figure 3. Forecast for residential PV by ENWL from 2014 (total dispersion in network).

\subsubsection{Energy Storage Scenarios}

Two energy storage scenarios are considered:

1. Storage is located in homes by PV owners who want to maximise their self-consumption. These are purchased in a free market so, like PV, the DNO cannot determine where they will be located. It is assumed storage will absorb peak generation i.e., it has a rating of $P_{\mathrm{ES}}=3.6 \mathrm{~kW}$ and is single phase. 
2. Storage is located in the street by the DNO to alleviate overvoltage. Three phase $25 \mathrm{~kW}$ units are selected based upon a survey of similar systems $[27,28]$. Locations are determined using the genetic algorithm described previously.

\subsubsection{Loads}

To determine the voltage ranges on the network, we perform two load flows to determine the maximum and minimum voltage. This avoids the computational effort of a high resolution load flow analysis and allows the model to determine the performance limits of the networks. In accordance with ENWL design policy, the after diversity maximum demand (ADMD) of domestic customers is $1.4 \mathrm{~kW}$ or $1 \mathrm{~kW}$. To identify which is appropriate for each LV network, $n$, a maximum demand of $1.4 \mathrm{~kW}$ is applied to each load in the network. If this causes under-voltage, a $1 \mathrm{~kW}$ ADMD is instead applied. The minimum daytime demand is assumed to be $0.142 \mathrm{~kW}$ [29]. The minimum and maximum demands are based on measurements of secondary transformers in real LV networks by the DNO.

\subsubsection{Network Voltage Deviation}

Since the GIS model has not been used to generate MV network models, assumed MV network voltage ranges, $\Delta V_{\mathrm{T}}$, need to be applied. Here, the MV voltage deviation is calculated using two voltage sensitivity factors from network nodes on a typical ENWL urban MV feeder. These are shown below (3) and (4). Each network is randomly assigned to one of these two factors to determine the voltage headroom. The parameter $X$ is defined by (5) and varies depending on whether the scenario is without storage, with domestic storage, or with storage connected directly onto the network.

$$
\begin{gathered}
\Delta V_{\mathrm{T}}=0.037+0.0216\left(p_{n}-X\right) \\
\Delta V_{\mathrm{T}}=0.028+0.0144\left(p_{n}-X\right) \\
X=0[\text { no storage }] \\
X=q_{n}[\text { domestic storage }] \\
X=\frac{25 N_{\mathrm{ESS}}}{3.6}[\text { network connected storage }]
\end{gathered}
$$

\subsubsection{Financial Model}

At the time of writing, lithium ion batteries represent the most widely deployed battery type in residential power networks. Lithium battery prices have fallen $45 \%$ in the period $2016-2017$, so the costs used here must be understood as those valid at the time of writing and therefore are likely an underestimate as battery costs fall. Representative battery costs have been sourced through an industrial survey as well as literature search [30].

The model in [31] is adapted to calculate the storage cost. Here, the discounted storage cost, $C_{\mathrm{ES}}$, is the sum of capital, $C_{\mathrm{CAP}}$, discounted maintenance, $C_{\mathrm{M}}$, losses, $C_{\mathrm{L}}$, and replacement, $C_{\mathrm{RP}}$, Equations (7)-(10).

$$
\begin{gathered}
C_{\mathrm{ES}}=C_{\mathrm{CAP}}+C_{\mathrm{RP}}+C_{\mathrm{M}}+C_{\mathrm{L}} \\
C_{\mathrm{CAP}}=C_{\mathrm{I}}+C_{\mathrm{P}} P_{\mathrm{ES}}+C_{\mathrm{C}}\left(\frac{P_{\mathrm{ES}} t \sqrt{\eta}}{D}\right) \\
C_{\mathrm{RP}}=C_{\mathrm{C}}\left(\frac{P_{\mathrm{ES}} t \sqrt{\eta}}{D}\right) \\
C_{\mathrm{L}}=C_{\mathrm{LI}} \cdot t D N_{\mathrm{C}}(1-\eta)
\end{gathered}
$$

$C_{P}$ is the cost of power, and $C_{C}$ is the discounted cost of energy. Storage parameters and costs are shown in Table 3. 
Table 3. Summary of energy storage cost parameters.

\begin{tabular}{ccc}
\hline Parameter & Symbol & Value \\
\hline Round trip efficiency (\%) [32] & $\eta$ & $80 \%$ \\
Storage time (h) & $t$ & 2.5 \\
Project life (years) & $N_{\mathrm{C}}$ & 10 \\
Operating days (per year) & $D$ & 200 \\
Depth of discharge (\%) & $i$ & $40 \%$ \\
Inflation rate & $d$ & $6 \%$ \\
Discount rate & $C_{\mathrm{LI}}$ & 0.06 \\
Electricity loss cost $(£ / \mathrm{kWh})[33]$ & $C_{\mathrm{M}}$ & 1.50 \\
Annual maintenance $(£ / \mathrm{kW})[32]$ & $P_{\mathrm{ES}}$ & 3.6 \\
Storage rating (storage in home) $(\mathrm{kW})$ & $C_{\mathrm{I}}$ & 400 \\
Storage in home install cost $(£)$ & $C_{\mathrm{ES}}$ & 5558 \\
Storage in home unit cost $(£ / \mathrm{system})$ & $P_{\mathrm{ES}}$ & 25 \\
Storage rating (DNO storage) $(\mathrm{kW})$ & $C_{\mathrm{I}}$ & 8000 \\
DNO storage install cost $(£)$ & $C_{\mathrm{ES}}$ & 43,825 \\
DNO storage unit cost $(£ /$ system) &
\end{tabular}

\subsubsection{Reinforcement Costs}

For all LV feeders, the reinforcement cost is the product of the length of a feeder and the unit cost of reinforcement. The budgetary unit cost used by the DNO is $£ 80 / \mathrm{m}$ as described in Section 3.4.1.

\section{Results}

\subsection{Base Case}

The method is first used to study the effect of PV on the LV network. Figure 4 shows the number of feeders from the GIS data which are forecast to experience overvoltage. It can be seen that the number of problematic feeders follows the same trend as the PV growth scenarios. The number of problematic feeders is different between the scenarios however. Of the 43,816 feeders assessed, only a small fraction is found to experience voltage issues due to PV integration. This is important, as it shows that most of the LV networks will be able to withstand the projected PV growth. DNOs need to identify the specific problematic feeders in their networks and provide mitigation solutions. This cannot be achieved by studies on generic networks, the actual networks on the ground need to be assessed.

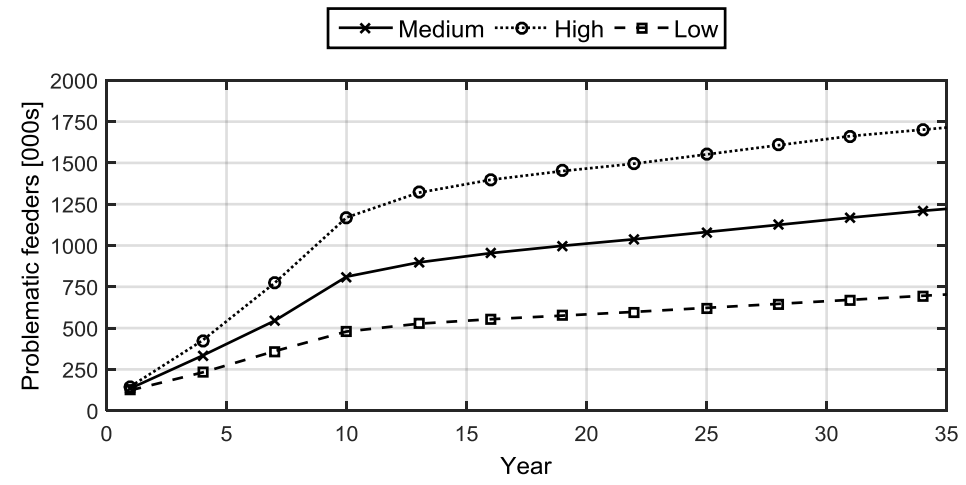

Figure 4. Number of problematic feeders under different PV growth scenarios.

By multiplying the length of each problematic feeder by a re-conductoring cost $(£ 80 / \mathrm{m})$, the method assesses the default cost to the DNO (Figure 5). Results show that the DNO will see increasing re-conductoring costs which closely mirror the shape of the underlying PV forecasts (Figure 5). Although the number of problematic feeders is relatively small, there is still a sizable financial cost for the DNO to maintain voltage limits. 


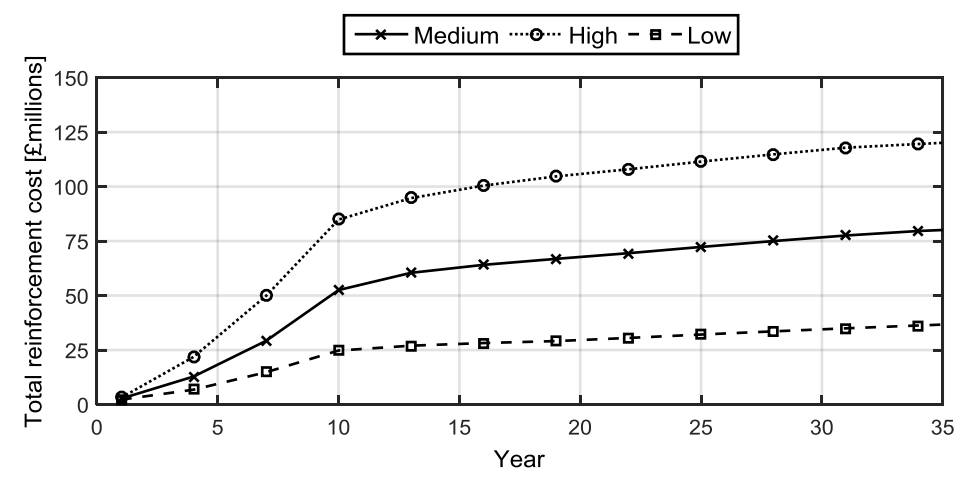

Figure 5. Cost to re-conductor problematic feeders at a cost of $£ 80 / \mathrm{m}$ and an entire feeder is reconductored if there is overvoltage. Cash flows are discounted.

\subsection{Comparison of Storage Scenarios on One Network}

The method for comparing storage is first applied to one network to illustrate the storage scenarios. Figure 6 shows the network voltages with PV on $100 \%$ of suitable homes and no storage (base case). It can be seen that feeder 2, between bus 48 and 98 , has overvoltage.
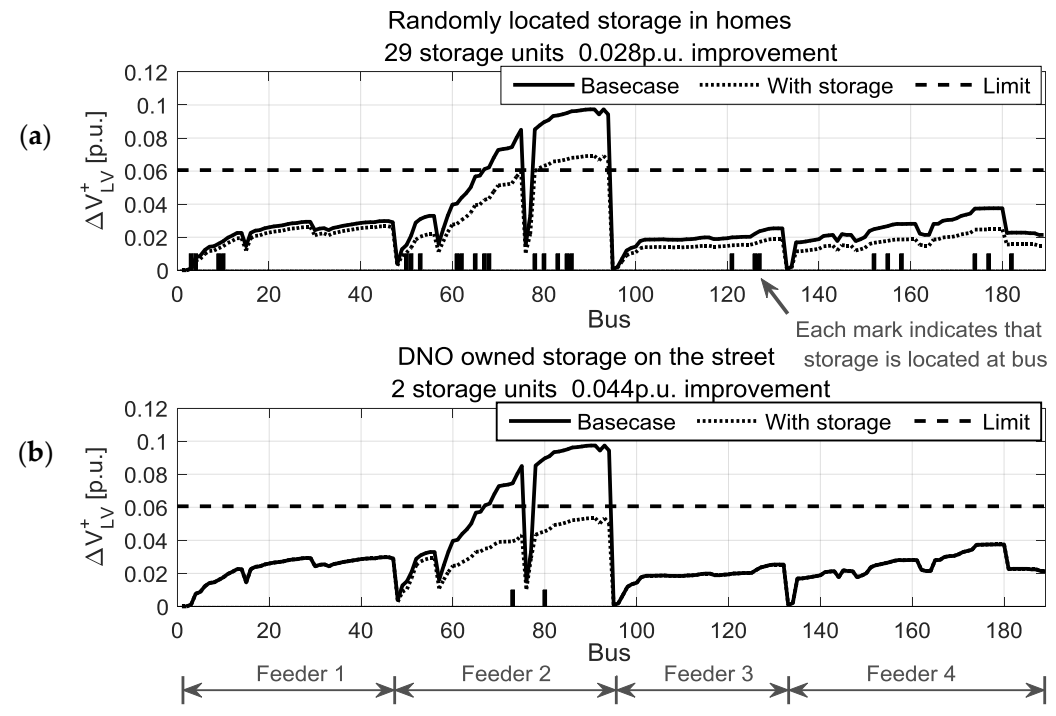

Figure 6. Application of the method to a single LV network. $100 \%$ of suitable roofs have PV. (a) shows the application of the tool with randomly located single phase storage of rating $3.6 \mathrm{~kW}$ and (b) shows three phase $25 \mathrm{~kW}$ storage which is strategically located by the DNO.

Storage is then assessed. In Figure 6a a random selection (25\%) of homeowners with PV install storage at locations denoted by the bars on the x-axis. The 29 storage systems reduce the voltage rise as shown by the change to the voltage profiles in the figure. Not all overvoltage conditions are removed, and so the DNO would still need to reinforce the network. Figure $6 \mathrm{~b}$ shows the same PV scenario, however in this case the DNO has installed two three-phase $25 \mathrm{~kW}$ storage units at locations determined by the genetic algorithm. The load flow shows that the network operation is within voltage limits in this scenario as expected by applying this algorithm.

In this network, $50 \mathrm{~kW}$ of DNO owned storage is used to manage voltage, compared to $104.4 \mathrm{~kW}$ of customer owned storage: and the latter does not solve the overvoltage. In feeder 2, which is the section of the network experiencing overvoltage in the base case, there is a comparable amount of home or DNO storage, but the DNO owned assets are located in such a way to have the capability to manage the overvoltage. 


\subsection{Assessment of LV Networks across DNO License Area}

The previous result is only applicable to one network, so a study of all 9163 networks $(43,816$ feeders) was then undertaken to compare the impact of storage (under the two installation scenarios) across this large population of networks.

The number of feeders in the entire set of 9163 networks which will experience overvoltage under a number of storage adoption scenarios and the medium PV integration scenario are shown in Figure 7. It can be seen that randomly located storage does reduce the number of feeders with overvoltage. However, even with storage in $15 \%$ of homes with PV, $78 \%$ of the problematic LV networks still need reinforcement. DNO sited storage is, by nature of the algorithm, able to solve overvoltage unconditionally.

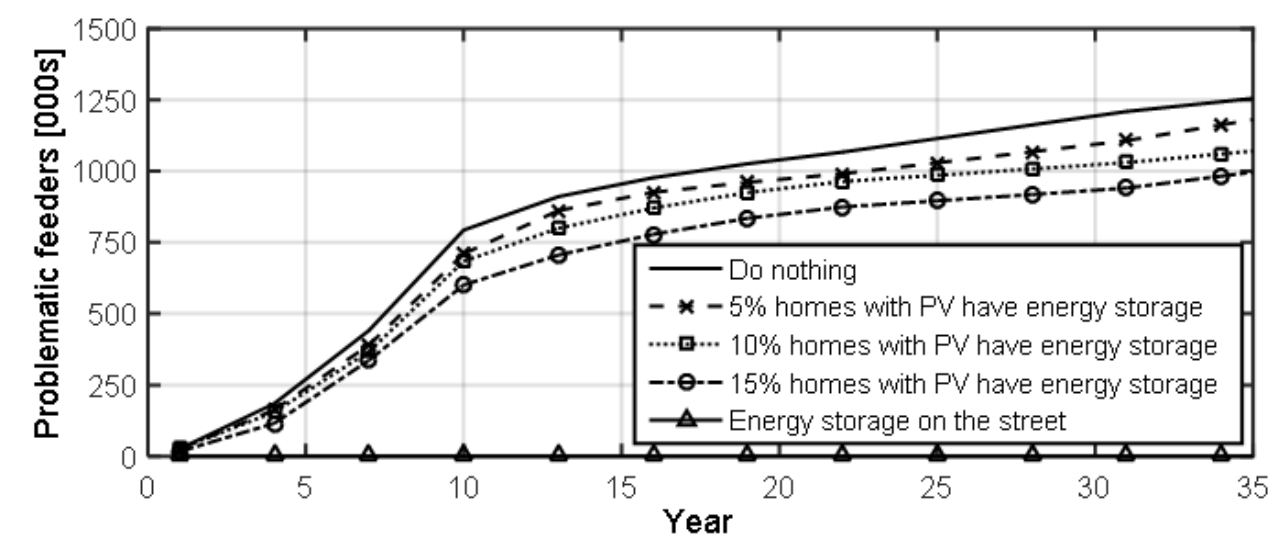

Figure 7. Number of problematic LV feeders in the entire network according to medium PV scenario with no storage, storage randomly located in different percentages of homes and storage located by the DNO.

The amount of storage installed under all PV scenarios is shown in Figure 8. The volume of DNO sited storage is comparable to installing storage in approximately $5 \%$ of homes in the network. It can also be seen that the potential market for such storage is uncertain (10 MW for low PV scenario, up to $50 \mathrm{MW}$ for high PV scenario, over 35 years). This uncertainty is important for manufacturers as well as DNOs.

The total reinforcement cost that the DNO will experience under all storage scenarios is shown in Figure 9. Randomly located storage does reduce the reinforcement costs, but this reduction is only a small fraction of the base case "do nothing" cost. It is observed that such storage has an alternative revenue stream from providing benefits to customers through bill reduction and self-consumption. This is addressed in the discussion.

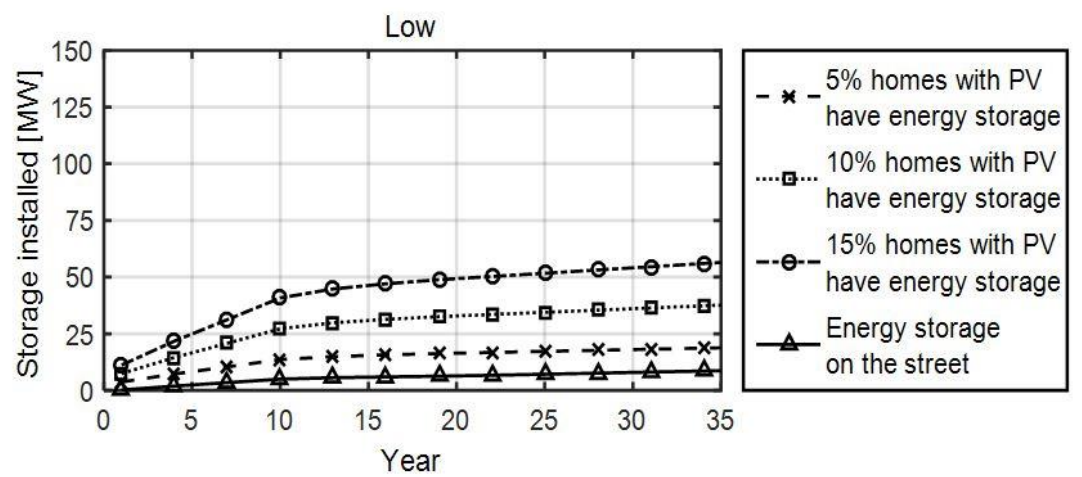

(a)

Figure 8. Cont. 


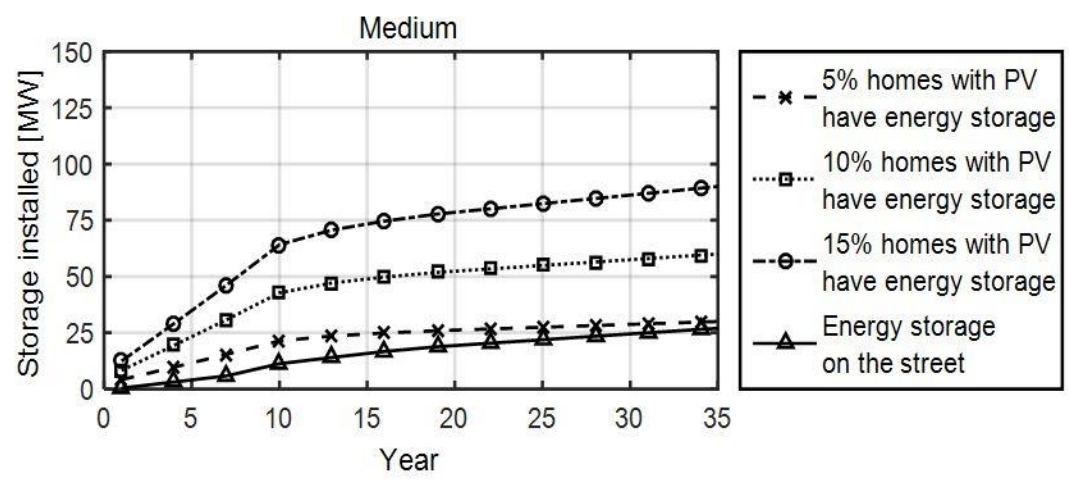

(b)

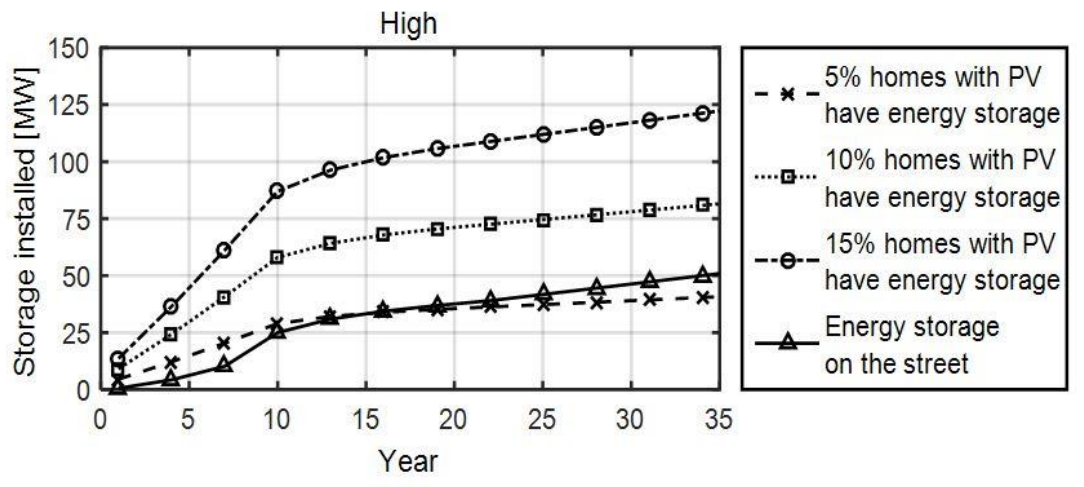

(c)

Figure 8. The capacity of storage installed both with storage randomly located in homes, and DNO installed storage, for (a) low; (b) medium; and (c) high PV penetrations.

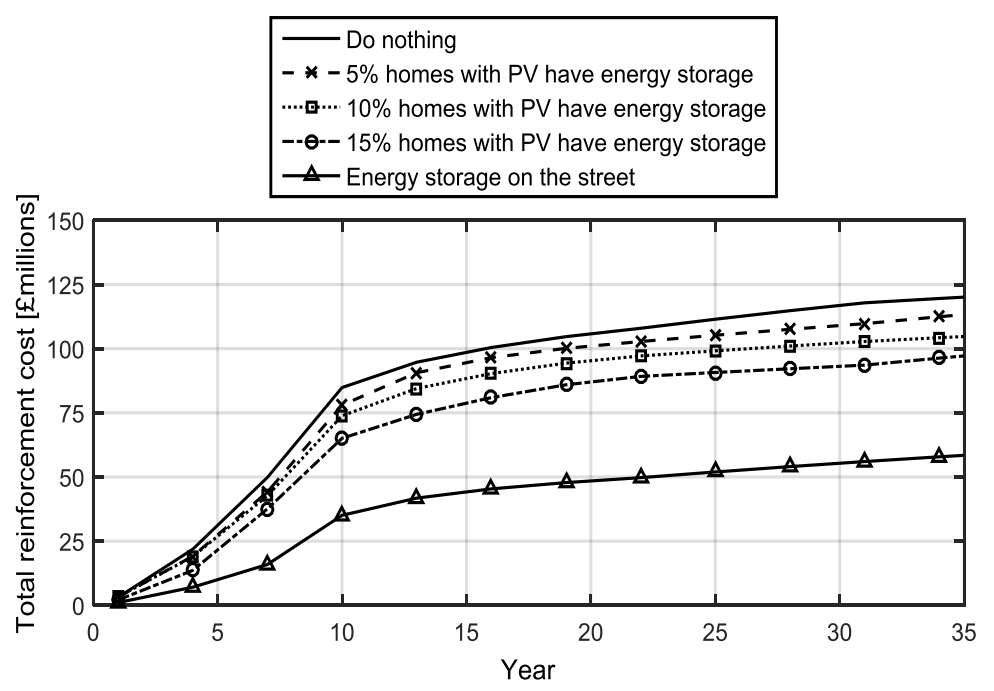

Figure 9. Total reinforcement cost when the DNO has to re-conductor despite either storage in homes or located by the DNO to prevent overvoltage, high PV scenario. The cost of storage is only included in the 'energy storage on the street' case as only the costs to the DNO are considered.

\subsection{Sensitivity Analysis}

A sensitivity analysis with respect to the cost of a complete energy storage system was performed. The number of networks where the DNO choses to re-conductor or choses to install energy storage is found to be dependent on the unit cost of storage as is demonstrated in Figure 10. In $94 \%$ of the problematic networks, energy storage is found to be economically favourable to traditional network 
reinforcement for managing overvoltage when the energy storage cost is $£ 200 / \mathrm{kWh}$. Note that the installation costs $C_{I}$ are kept constant and so only savings in energy storage are included in the energy storage price scenarios.

With a low PV dispersion level across the entire DNO network, the economic case for energy storage is found to be favourable in comparison with re-conductoring. In the base case, storage is selected in $100 \%$ of the networks where the storage cost is less than $£ 600 / \mathrm{kWh}$. As the PV dispersion level increases, the severity of voltage problems increases. Consequently, the capacity of energy storage required to manage voltage problems increases. The incremental cost of adding energy storage systems in problematic networks is found to decrease such that storage is selected in less than $50 \%$ of the problematic networks with a storage cost of $£ 800 / \mathrm{kWh}$.

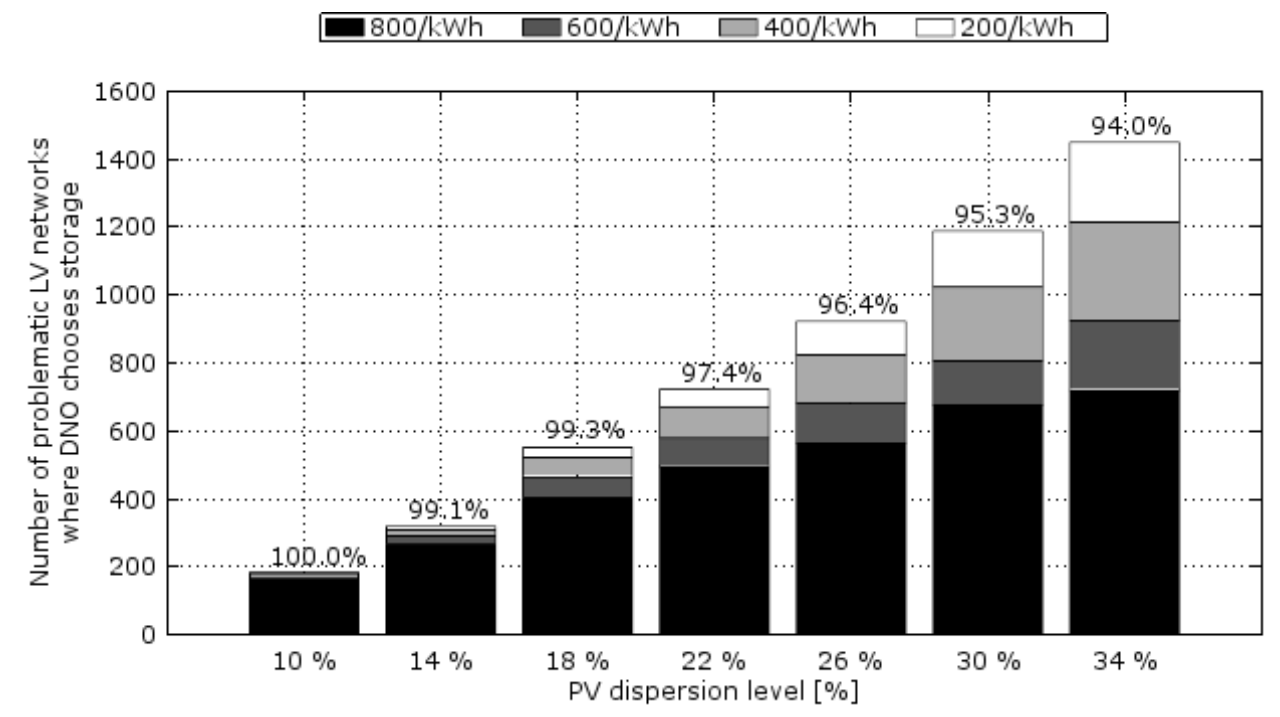

Figure 10. Number of networks where DNO choses storage over re-conductoring under different energy storage price scenarios. The percentage of networks where a DNO chooses energy storage is shown above each of the bars.

\subsection{Comparison with Existing UK Power System Storage}

The scale of the distributed storage, for one network area in the UK, can be compared with existing storage in the UK power system, which in this instance takes the form of pumped hydro. As shown in Table 4, LV energy storage located by a DNO is small compared to existing pumped storage plant capacity. Wide adoption of energy storage by customers may provide comparable power but this would not necessarily be as available as pumped storage. Should the DNO storage scenario be repeated across all UK mainland areas, the energy capacity would be of a similar order to Ffestiniog pumped hydro station.

Table 4. Comparison between distributed storage to existing pumped hydro (PH) and battery systems in the UK. LV storage is rated for $5 \mathrm{~h}$ and shown only for homes in the ENWL license area.

\begin{tabular}{cccc}
\hline Name & $\begin{array}{c}\text { Capacity, } \\
\text { GWh }\end{array}$ & Power, MW & $\begin{array}{c}\text { Location in } \\
\text { Network }\end{array}$ \\
\hline Dinorwig [PH] & $\sim 10$ & 1728 & Transmission \\
Ffestiniog [PH] & 1.3 & 360 & $\sim 45$ \\
\\
\hline Storage in 5\% of homes with PV, year 35, high PV forecast & $\sim 0.140$ & $\sim 124$ & LV network \\
Storage in 15\% of homes with PV, year 35, high PV forecast & $\sim 0.463$ & $\sim 50$ & \\
DNO storage, year 35, high PV forecast & $\sim 0.125$ & & \\
\hline
\end{tabular}




\section{Discussion}

The results of this work show that storage should be carefully located within an LV network using a heuristic method to minimise a DNO's overall cost. Storage may still offer benefits to homeowners and that does have a benefit to DNOs in reducing reinforcement costs. However, it is found that storage in homes will not prevent all overvoltage, because the location of the storage in networks is not optimised for overvoltage reduction in this case.

Social factors will also be important to consider, such as engagement with specific customers by DNOs to target installation of residential storage. For example, it could be suggested that storage is targeted by DNOs at homes with PV who are experiencing voltage problems. This would mean storage is installed in homes on problematic networks with the objective of reducing overall costs. In this case, there would be a benefit both for the DNO and to homeowners in reduced curtailment and lower network costs. The DNO might pass financial benefits of avoided re-conductoring to customers with storage as a local subsidy as presented in [25]. Battery and PV/battery hybrid inverters commonly contain the control logic required for export limitation or non-greedy self-consumption as would be required to maintain network voltage limits. The inverter might also call upon demand side loads such as storage heaters, electric vehicles or smart appliances-which would improve the chances of a load/store being available to maintain voltage limits.

Storage located by the network operator could be built with control algorithms which are targeted towards a DNO objective of voltage control [34,35]. Street storage itself might be favourable for DNOs as it does not need to be located in customer homes. This avoids issues such as the need to fundamentally change the relationship between the DNO and homeowners. However, it may be difficult to install such storage where there is limited space on the street or concerns of theft or damage.

Technical and financial parameters have been used for this study which have been accepted by DNOs for works previously published by the authors [24]. In the future, DNOs will need to recalculate results if parameters change. For example, DNOs might also model an increase in peak demand if there is widespread adoption of electric vehicles and heat pumps in the future. This is easily achieved in the tool through adjusting the parameters described in Section 3.4.4. As the economics of energy storage improve, such as through reduced battery costs, increased variable electricity prices or through smart tariffs then their dispersion level will be much higher. Further study should evaluate the dispersion level for storage in homes which achieves comparable economic results for the DNO.

This work was completed as an electrical energy storage study. Other technologies such as electric vehicles, flexible heat pumps, thermal storage, occupancy patterns [36], or measured data can be included in the model by adjusting the maximum or minimum demand in the networks. Adaptation of the model in this paper would therefore allow assessment of integration of a number of network changes. Hot water storage is very common in the UK, for example, and the DNO might consider that adoption of thermal storage linked to PV will be more widespread than adoption of batteries in customers' homes.

Curtailment of PV is one of the primary practical implications of overvoltage in LV networks. The amount of curtailment could be calculated by extending the model to include annual demand and generation forecasts. Such modelling would allow the DNO to select networks with the worst voltage problems and those where the most curtailment will occur. This is important to allow the DNO to determine networks where curtailment is most extreme and where mitigating actions should be prioritised. Furthermore, if the overvoltage and curtailment is small, then there is an important case to be made to regulators to allow some PV curtailment in connection agreements if this reduces the overall reinforcement cost. For example, the connection agreement could ensure that the PV is not curtailed for more than a set number of hours in a year with the length of time of each curtailment also limited.

It should be noted that calculation of problematic feeder is based on an assumption that minimum load and maximum output coincide, and that maximum output is at the rated power $\mathrm{P}_{\mathrm{PV}}$. This is a common approach, taking a worst case scenario. In reality, for the UK the amount of time for which 
output power is at rated is very small, and therefore UK DNOs may wish to consider a probabilistic approach to the combination of low load and high PV output.

\section{Conclusions}

This paper has presented a method for assessing the impact of residential PV and energy storage on overvoltage in a large number of LV networks. This has been applied to 9163 LV networks, comprising 43,816 feeders, in the North West of the UK. It has shown that storage should be carefully located within an LV network using a heuristic method to reduce the cost of storage and the overall reinforcement cost to prevent overvoltage. Widespread adoption of stochastically located storage in homes is unlikely to prevent all overvoltage since the location is critical. Even so, storage in homes may have additional benefits where voltage problems are present. As shown in the economic sensitivity analysis, the need for storage increases with the PV dispersion levels but so does the requirement for reduced costs of storage.

Author Contributions: A.F.C. designed and implemented the computational techno-economic model as part of his $\mathrm{PhD}$ under the supervision of N.S.W. D.J. provided the network models on which the analysis is performed and provided validation of the DNO relevance of the models. S.L.W. provided oversight of the paper and assisted in the drafting of the results for this journal. All authors discussed the results, how best to present them and contributed to the writing of the paper.

Funding: This work was supported by Electricity North West, Ltd., and Scottish Power Energy Networks, through Ofgem's Innovation Funding Initiative.

Conflicts of Interest: The authors declare no conflicts of interest.

\section{References}

1. Department for Business, Energy \& Industrial Strategy. Solar Photovoltaics Deployment. 2017. Available online: https://www.gov.uk/government/statistics/solar-photovoltaics-deployment (accessed on 20 November 2017).

2. Shahnia, F.; Majumder, R.; Ghosh, A.; Ledwich, G.; Zare, F. Voltage imbalance analysis in residential low voltage distribution networks with rooftop PVs. Electr. Power Syst. Res. 2011, 81, 1805-1814. [CrossRef]

3. Collins, L.; Ward, J.K. Real and reactive power control of distributed PV inverters for overvoltage prevention and increased renewable generation hosting capacity. Renew. Energy 2015, 81, 464-471. [CrossRef]

4. Jayasekara, N.; Wolfs, P.; Masoum, M.A.S. An optimal management strategy for distributed storages in distribution networks with high penetrations of PV. Electr. Power Syst. Res. 2014, 116, 147-157. [CrossRef]

5. Ratnam, E.L.; Weller, S.R.; Kellett, C.M. An optimization-based approach to scheduling residential battery storage with solar PV: Assessing customer benefit. Renew. Energy 2015, 75, 123-134. [CrossRef]

6. Kabir, M.N.; Mishra, Y.; Ledwich, G.; Xu, Z.; Bansal, R.C. Improving voltage profile of residential distribution systems using rooftop PVs and Battery Energy Storage systems. Appl. Energy 2014, 134, 290-300. [CrossRef]

7. Petinrun, J.O.; Shaaban, M. Impact of renewable generation on voltage control in distribution systems. Renew. Sustain. Energy Rev. 2016, 65, 770-783. [CrossRef]

8. Green, J.P.; Smith, S.A.; Strbac, G. Evaluation of electricity distribution system design strategies. IEE Proc. Gener. Transm. Distrib. 1999, 146, 53-60. [CrossRef]

9. Li, Y.; Wolfs, P. Taxonomic description for western Australian distribution medium-voltage and low-voltage feeders. IET Gener. Transm. Distrib. 2014, 8, 104-113. [CrossRef]

10. Scottish and Southern Energy Power Distribution. LCNF Tier 1 Close down Report Low Voltage Network Modelling and Analysis Environment Project Ref. SSEPDT1005; Southern Electric Power Distribution: Perth, UK, 2013.

11. Erdinc, O. Economic impacts of small-scale own generating and storage units, and electric vehicles under different demand response strategies for smart households. Appl. Energy 2014, 126, 142-150. [CrossRef]

12. Li, J.; Danzer, M.A. Optimal charge control strategies for stationary photovoltaic battery systems. J. Power Sources 2014, 258, 365-373. [CrossRef] 
13. Vieira, F.M.; Moura, P.S.; de Almeida, A.T. Energy storage system for self-consumption of photovoltaic energy in residential zero energy buildings. Renew. Energy 2017, 103, 308-320. [CrossRef]

14. Mégel, O.; Mathieu, J.L.; Andersson, G. Scheduling distributed energy storage units to provide multiple services under forecast error. Int. J. Electr. Power Energy Syst. 2015, 72, 48-57. [CrossRef]

15. Sue, K.; MacGill, I.; Hussey, K. Distributed energy storage in Australia: Quantifying potential benefits, exposing institutional challenges. Energy Res. Soc. Sci. 2014, 3, 16-29. [CrossRef]

16. Moshövel, J.; Kairies, K.-P.; Magnor, D.; Leuthold, M.; Bost, M.; Gährs, S.; Szczechowicz, E.; Cramer, M.; Sauer, D.U. Analysis of the maximal possible grid relief from PV-peak-power impacts by using storage systems for increased self-consumption. Appl. Energy 2015, 137, 567-575. [CrossRef]

17. Crossland, A.; Jones, D.; Wade, N.S. Energy Storage/Demand Side Response in LV Networks: Design of Cost Based Planning Tools for Network Operators. In Proceedings of the 22nd International Conference on Electricity Distribution (CIRED), Stockholm, Sweden, 10-13 June 2013.

18. Yunusovm, T.; Frame, D.; Holderbaum, W.; Potter, B. The impact of location and type on the performance of low-voltage network connected battery energy storage systems. Appl. Energy 2016, 165, 202-213. [CrossRef]

19. British Standards Institution. BS EN 50160:2007 Voltage Characteristics of Electricity Supplied by Public Distribution Networks; British Standards Institution: London, UK, 2007.

20. Kolenc, M.; Papič, I.; Blažič, B. Assessment of maximum distributed generation penetration levels in low voltage networks using a probabilistic approach. Int. J. Electr. Power Energy Syst. 2015, 64, 505-515. [CrossRef]

21. Navarro, A.; Ochoa, L.F.; Randles, D. Monte Carlo-based assessment of PV impacts on real UK low voltage networks. In Proceedings of the IEEE Power and Energy Society General Meeting, Vancouver, BC, Canada, 21-25 July 2013; pp. 1-5.

22. Nick, M.; Cherkaoui, R.; Paolone, M. Optimal siting and sizing of distributed energy storage systems via alternating direction method of multipliers. Int. J. Electr. Power Energy Syst. 2015, 72, 33-39. [CrossRef]

23. Huang, X.; Zhang, G.; Xiao, L. Optimal location of SMES for improving power system voltage stability. IEEE Trans. Appl. Supercond. 2010, 20, 1316-1319. [CrossRef]

24. Crossland, A.F.; Jones, D.; Wade, N.S. Planning the location and rating of distributed energy storage in LV networks using a genetic algorithm with simulated annealing. Int. J. Electr. Power Energy Syst. 2014, 59, 103-110. [CrossRef]

25. Crossland, A.F. Application of Stochastic and Evolutionary Methods to Plan for the Installation of Energy Storage in Voltage Constrained LV Networks. Ph.D. Thesis, Durham University, Durham, UK, 2014.

26. HM Government. The Electricity Safety, Quality and Continuity Regulations 2002; HM Government: London, UK, 2002.

27. DOE Global Energy Storage Database. DOE Global Energy Storage Database SMUD PV E Smart Grid Pilot at Anatolia. 2014. Available online: https:/ / www.energystorageexchange.org/ (accessed on 15 April 2014).

28. Southern Electric Power Distribution. Low Carbon Networks Fund Full Submission Pro-Forma; 2011. Available online: https:/ / www.ofgem.gov.uk/ofgem-publications/46055/ntvvproformaappendices.pdf (accessed on 15 April 2014).

29. Electricity North West Limited. Low Carbon Network Fund Project ENWT1001-The Smart Fuse-Closedown Report; Electricity North West Limited: London, UK, 2014.

30. Eller, A.; Gauntlett, D. Energy Storage Trends and Opportunities in Emerging Markets; Navigant Consulting Inc.: Boulder, CO, USA, 2017.

31. Schoenung, S.M.; Hassenzahl, W.V. Long- vs. Short-Term Energy Storage Technologies Analysis a Life-Cycle Cost Study; Sandia National Laboratories: Albuquerque, NM, USA, 2003.

32. Schoenung, S.M. Energy Storage Systems Cost Update; Sandia National Laboratories: Albuquerque, NM, USA, 2011.

33. Office of Gas and Electricity Markets. Electricity Distribution Price Control Review Final Proposals 145/09; OFGEM: London, UK, 2009.

34. Mokhtari, G.; Nourbakhsh, G.; Ghosh, A. Smart coordination of energy storage units (ESUs) for voltage and loading management in distribution networks. IEEE Trans. Power Syst. 2013, 28, 4812-4820. [CrossRef] 
35. Wang, L.; Liang, D.; Crossland, A.F.; Taylor, P.C.; Jones, D.; Wade, N.S. Coordination of multiple energy storage units in a low voltage distribution network. IEEE Trans. Power Syst. 2015, 6, 2906-2918. [CrossRef]

36. Leicester, P.; Goodier, C.; Rowley, P. Evaluating self -consumption for domestic solar PV: Simulation using highly resolved generation and demand data for varying occupant archetypes. In Proceedings of the 2015 11th Photovoltaic Science, Applications and Technology Conference (PVSAT-11), Leeds, UK, 15-17 April 2015; pp. 89-92.

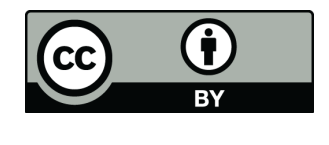

(C) 2018 by the authors. Licensee MDPI, Basel, Switzerland. This article is an open access article distributed under the terms and conditions of the Creative Commons Attribution (CC BY) license (http:/ / creativecommons.org/licenses/by/4.0/). 